\title{
Paleoseismicity: Extending the record of earthquakes into prehistoric time
}

In order to forecast earthquake activity, we need to determine the past history of faults. Working Group 1 of the Inter-Union Commission on the Lithosphere proposes to compile paleoseismicity data for active faults and subduction zones around the world, as well as for earthquake-producing zones in plate interiors. This information should help particularly in determining important factors such as the variability of recurrence intervals for earthquakes on a given fault ( $E d$.)

A fault that is active is likely to move again (Wallace, 1986). If the fault moves by strike-slip and produces earthquakes, then it is important to society to be able to forecast when the next displacement will occur. Forecasting future activity depends on developing and using information on the past behavior of the fault. One way to do this is to learn the slip rate, $v$, from offsets of geologic markers of known age. The surface displacement, $d$, is estimated for an earthquake characteristic of the fault. The recurrence interval, $r$, between successive earthquakes on the same fault is:

$$
r=d / v
$$

This method assumes that the fault will rupture the same amount in the next earthquake as it did in the last, and the method implies a uniform recurrence rate, a constant value of $r$. In nature, however, recurrence intervals can be variable.

As an example of the variability of recurrence intervals, Sieh and others (1989) identified 12 individual earthquakes at Pallett Creek on the Mojave segment of the San Andreas fault in California, USA. Using high-precision radiocarbon dating techniques for the last 10 earthquakes, they found that earthquakes tend to occur in clusters of 2 or 3 events that are separated by intervals of 200 to 330 years. They also found that the recurrence intervals between individual earthquakes vary from 44 to $332 \pm 15$ years (fig. 1). In comparison, the average recurrence interval of 132 years for the last 10 events at Pallett Creek is less than one-half of the average recurrence interval of several hundred years at Wallace Creek in the Carrizo segment of the fault (Sieh and others, 1989; see fig. $2 A$ for locations). The longer recurrence interval at Wallace Creek may result from its being a stronger fault zone, and the Mojave segment also may rupture independently in events that do not displace the stronger fault zone in the Carrizo Plain. Another possible explanation may be that Pallett Creek exposes a record of overlapping ruptures from the large earthquakes that nucleated on the San Bernardino Mountains and Coachella Valley segments to the southeast, as well as from large earthquakes on the Carrizo segment to the northwest (fig. $2 B$; compare Sieh and others, 1989).
Subduction-zone earthquakes appear to show the same variability in recurrence interval. These earthquakes may be recognized by evidence of sudden uplift or subsidence of upperplate crust as elastic strain in the upper plate is released (Atwater, 1987). Sudden uplift produces Holocene wave-cut benches, and sudden subsidence produces burial of salt marshes by supratidal muds and, in some cases, tsunami deposits. Darienzo and Peterson (1990) obtained a record of more than 3,000 years of marsh burial events at Netarts Bay on the northwestern Oregon coast, USA. They recognized subsidence events at $300-500,1,000-1,300,1,400-1,800$, and $3,000-$ 3,300 radiocarbon years before the present. The average recurrence interval is 600 years, but the range in recurrence intervals extends from fewer than 300 to 1,000 years.

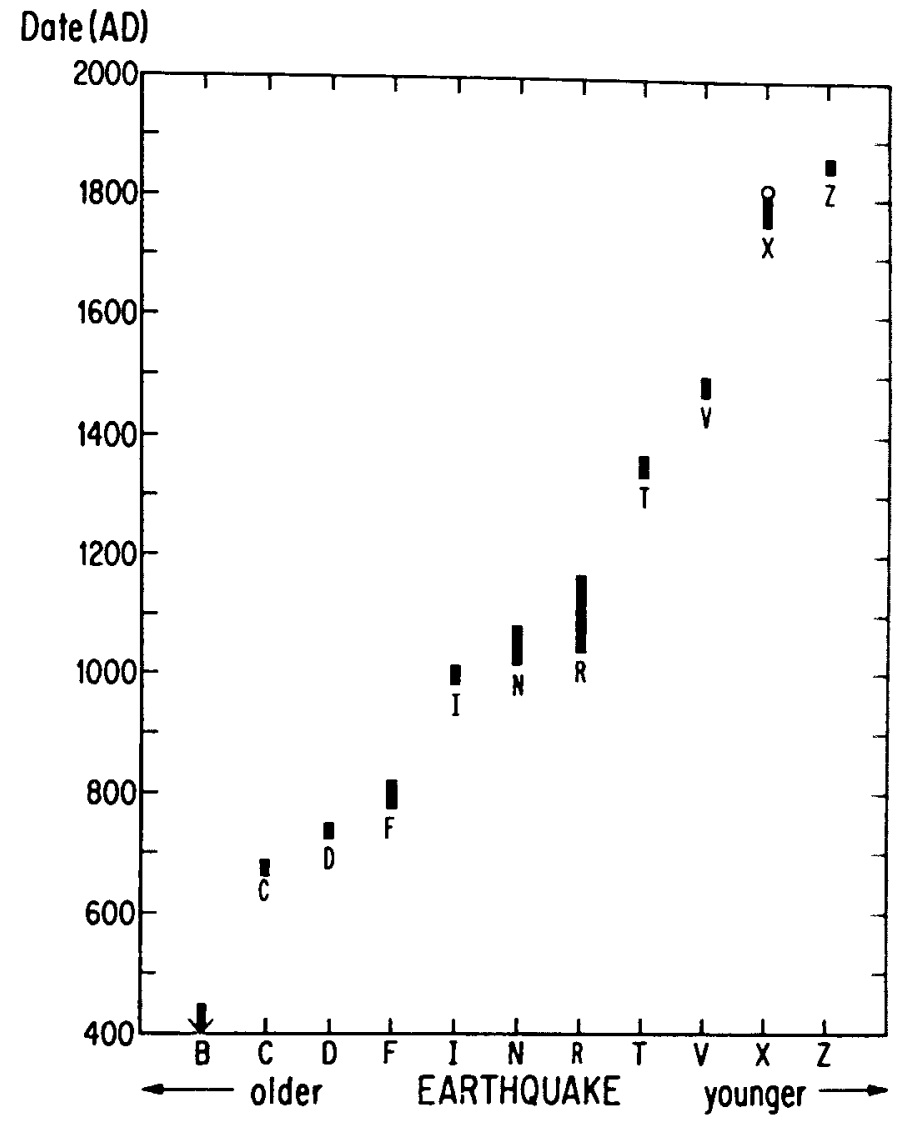

Figure 1. - New estimates of the dates for earthquakes recorded in the sediments at Pallett Creek on the San Andreas fault in California. Bars give 95 percent confidence intervals. Open circle on bar of event $X$ indicates preferred date of A.D. 1812. Taken from Sieh and others (1989). 


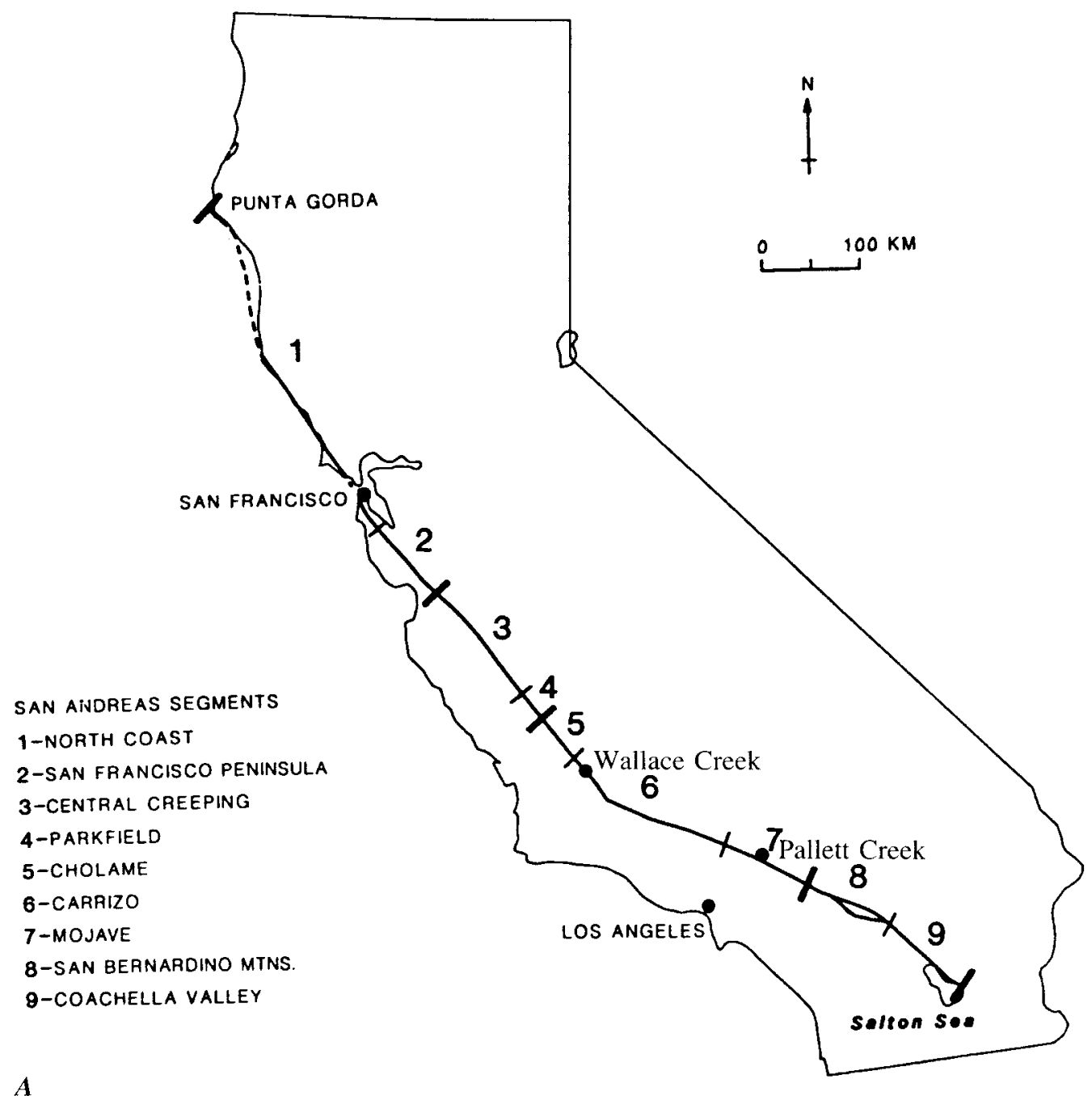

$A$

$B$

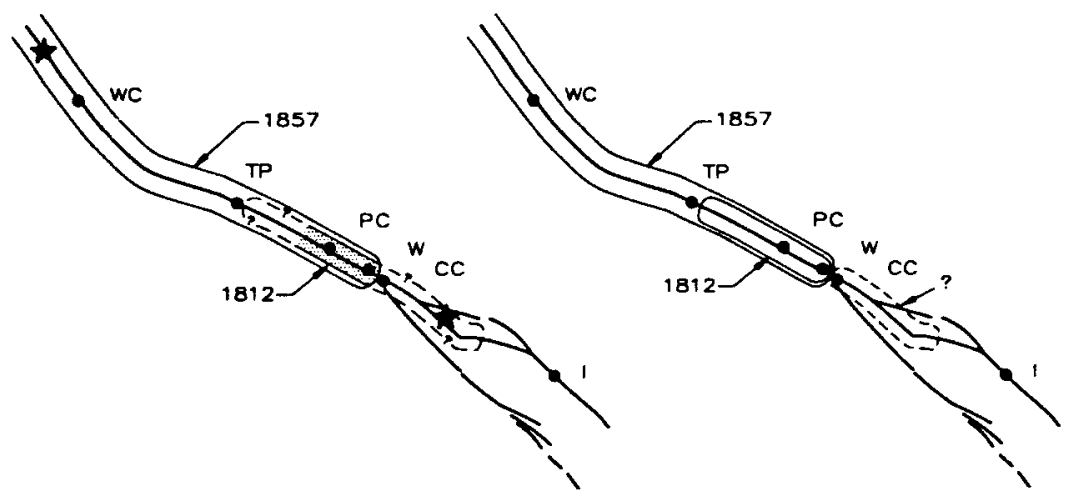

Figure 2.-Segmentation model for the San Andreas fault, California. A, Heavy-weight lines across the fault define major segments; shorter light-weight lines define subsegments and transition zones that may be independent segments. B, Earthquake scenarios on southern San Andreas fault segments. Left, 1857 and proposed 1812 earthquakes nucleate at stars and overlap in Mojave segment, as recorded at Pallett Creek. Mojave does not rupture as an independent segment. Right, Mojave is an independent subsegment, and San Bernardino (dashed line) also ruptures as an independent segment. Dots refer to paleoseismicity sites. Taken from Schwartz (1988) and Sieh and others (1989). 


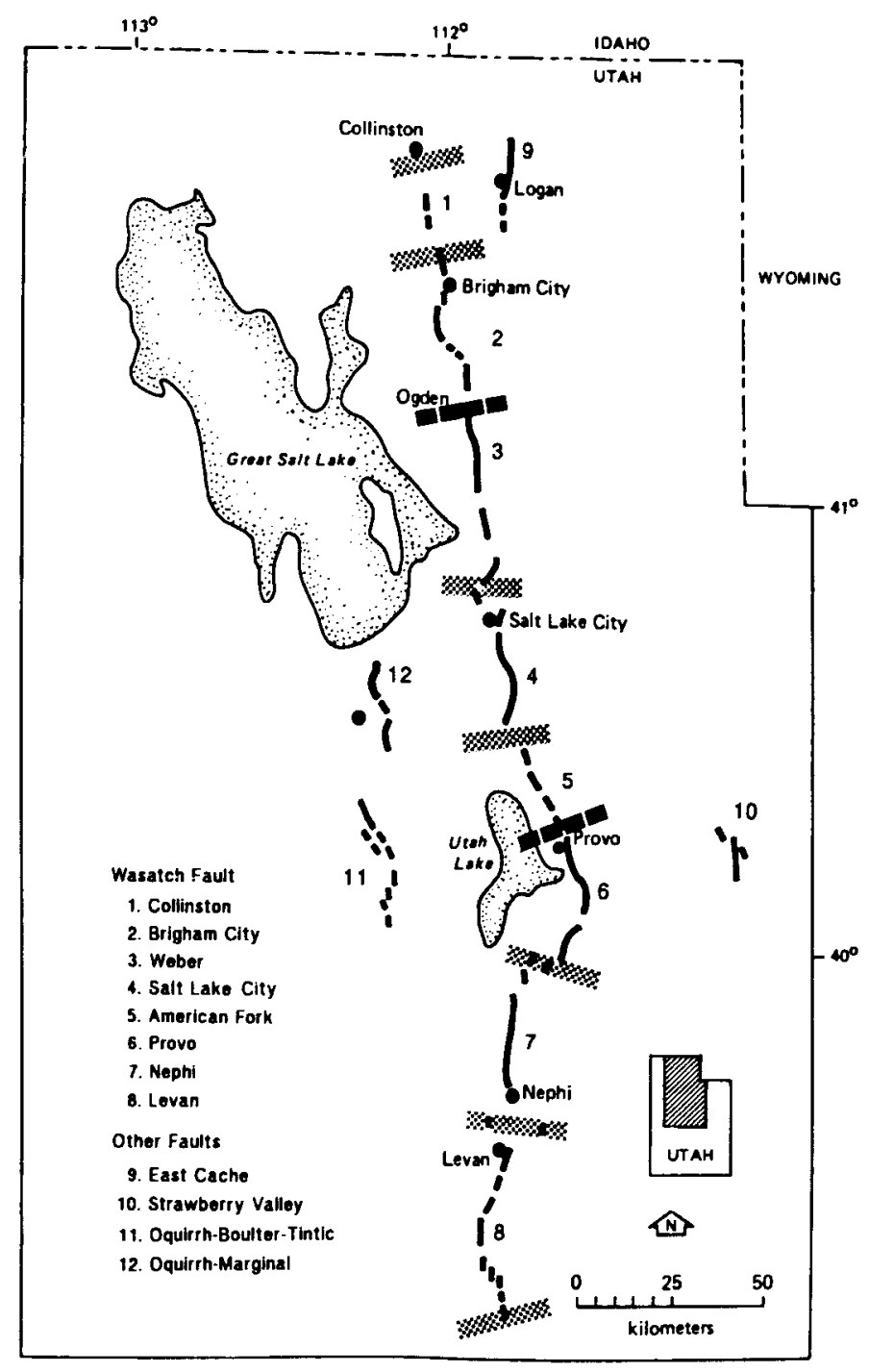

A

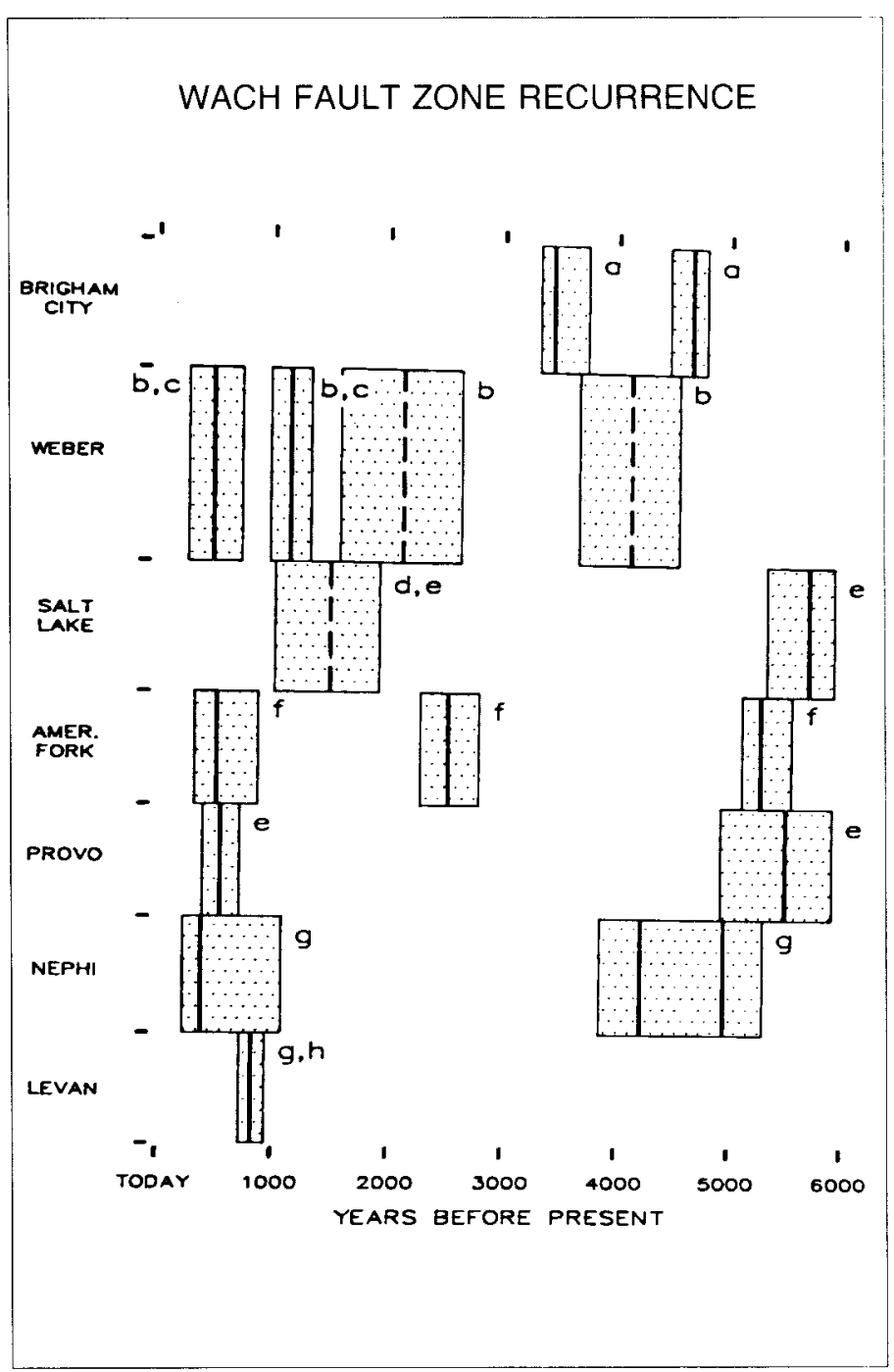

$\boldsymbol{B}$

Figure 3.-Segmentation model for the Wasatch fault, Utah. A, Stippled bands define segment boundaries identified by Schwartz and Coppersmith (1984); heavy dashed bands are additional boundaries interpreted by Machette and others (1987). B, Space-time plots of large-magnitude, scarp-forming earthquakes in the Wasatch fault zone during the past 6,000 years. Solid line shows the best estimate of the age of the event; dashed line shows the less well constrained age; stippled box shows the uncertainty in date. Letters a-h refer to source for timing of events. For sources of data, see Schwartz (1988), which is the source of this illustration.

Before we can understand the reasons for variability in the recurrence of earthquakes on a given fault, we need to map this variability for many individual faults and subduction zones. An example of the information needed is shown in the western United States for the Wasatch fault, the subject of an evaluation by the U.S. Geological Survey (Machette and others, 1987) of earthquake hazards in the Salt Lake City urban area. The fault was divided into segments on the basis of various criteria such as change in fault strike, location of transverse structures, and differences in slip rate and timing of past earthquakes (fig. $3 A$ ). The total long-term displacement is lower at the north and south ends of the fault zone and is higher in the middle. If displacement were to begin at the same time all along the fault, the central section should have the highest slip rate and should pose the greatest seismic threat.
No surface-rupturing historic earthquakes have been recorded on the Wasatch fault during the short period of about 150 years of record keeping there. However, numerous trenches have been excavated across the fault, and prehistoric earthquakes have been identified. These earthquakes are shown in figure $3 B$. This compilation shows the variability of recurrence intervals on individual fault segments, as well as the fact that some of the ruptures are limited to geologically defined individual segments, whereas other ruptures appear to cross segment boundaries.

As a contribution to the International Decade for Natural Disaster Reduction (IDNDR), Working Group 1 of the Inter-Union Commission on the Lithosphere (ICL) proposes to compile paleoseismicity data for active faults and subduction zones around the world by using the format described above for the Wasatch fault. 
This compilation should prove useful in assessing (1) the variability of earthquake recurrence intervals, (2) seismic slip as a function of slip rate and crustal rock type, (3) the reliability of geologically mapped segment boundaries in predicting the length of rupture zones, and (4) the repeatability of individual earthquake rupture zones along the same fault. In addition to plate boundaries and major intraplate faults, paleoseismicity information should be compiled for earthquake-producing zones in plate interiors, including the New Madrid, Missouri, Meers, Oklahoma, and Charleston, South Carolina, areas of the United States and the earthquake-induced surface ruptures in Australia.

The major difficulty in compiling paleoseismicity data is the imprecision of dating. For example, radiocarbon dates would include the 1939 to 1967 series of earthquakes along the North Anatolian fault of Turkey as a single earthquake or the 1944 and 1946 earthquakes of the Nankai Trough of Japan as a single earthquake. More precise dating using tree rings or varved sediments would improve matters but would not completely resolve the problem.

Persons interested in contributing to this key project of compiling paleoseismicity data for active faults and subduction zones around the world, as well as for earthquake-producing zones in plate interiors, should contact Robert S. Yeats, Chairman of Working Group 1 of ICL, at Oregon State University, Department of Geosciences, Corvallis, OR 97331, USA.

\section{References}

Atwater, B.F., 1987, Evidence for great Holocene earthquakes along the outer coast of Washington State: Science, v. 236, p. 942-944.

Darienzo, M., and Peterson, C., 1990, Episodic tectonic subsidence of late Holocene salt marshes, northern Oregon central Cascadia margin: Tectonics, v. 9, p. 1-22.

Machette, M.N., Personius, S.F., and Nelson, A.R., 1987, Quaternary geology along the Wasatch fault zone: Segmentation, recent investigations, and preliminary conclusions, in Hays, W.W., and Gori, P., eds.. Assessment of regional earthquake hazards and risk along the Wasatch Front, Utah: U.S. Geological Survey Open-File Report 87-585, p. A1-A72.

Schwartz, D.P., 1988, Geology and seismic hazards: Moving into the 1990's, in Von Thun, J.L., ed., Earthquake engineering and soil dynamics II-Recent advances in ground-motion evaluation: American Society of Civil Engineers, Park City, Utah, 1988, Proceedings, p. 1-42.

Schwartz, D.P., and Coppersmith, K.J., 1984, Fault behavior and characteristic earthquakes: Examples from the Wasatch and San Andreas faults: Journal of Geophysical Research, v. 89, p. 5681-5698.

Sieh, K., Stuiver, M., and Brillinger, D., 1989, A more precise chronology of earthquakes produced by the San Andreas fault in southern California: Journal of Geophysical Research, v. 94, p. 603-623.

Wallace, R.E., 1986, Overview and recommendations, in Wallace, R.E., chairman, Active tectonics, in the collection Studies in geophysics: Washington, D.C., National Academy Press, p. 3-19.

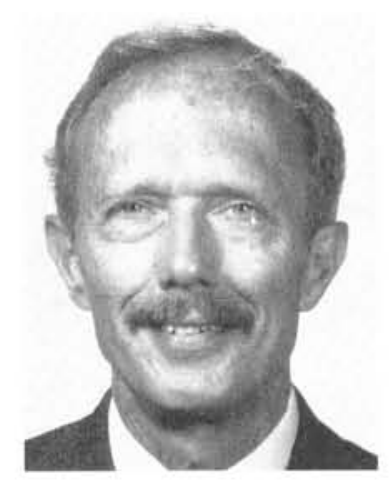

Dr. Robert S. Yeats is a Professor of Geology at Oregon State University, Corvallis, Oregon, USA. He received an undergraduate degree in geography from the University of Florida and his graduate degrees in geology from the University of Washington. After working for Shell Oil Company in southern California, he joined the geology faculty at Ohio University and then became Chairman of the Department of Geosciences at Oregon State University in 1977. His research interests focus on active folding and faulting in southern California, the Himalayan foothills, New Zealand, and western Oregon. He is Chairman of Working Group I, Inter-Union Commission on the Lithosphere, and a member of the Geophysics Study Committee, U.S. National Research Council.

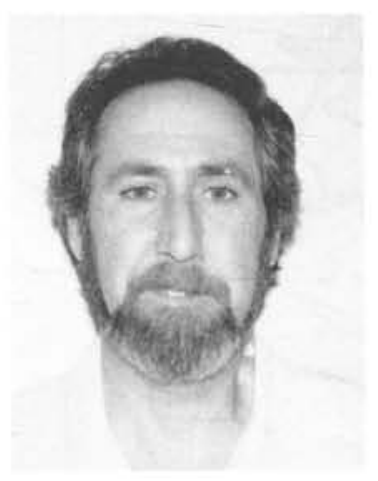

Dr. David P. Schwartz received his bachelor's and master's degrees in geology from the City University of New York and his doctorate from the State University of New York at Binghamton. He works at the U.S. Geological Survey in Menlo Park, California, as Chief of two projects dealing with earthquake recurrence on the San Andreas fault and in the intermountain seismic belt. Schwartz has studied active faults throughout the western United States, Central and South America, Japan, and Egypt. His trenching investigations have led to basic developments in paleoseismology, particularly with regard to identifying the signature of individual past earthquakes in the geologic record, their timing, and their size. 